
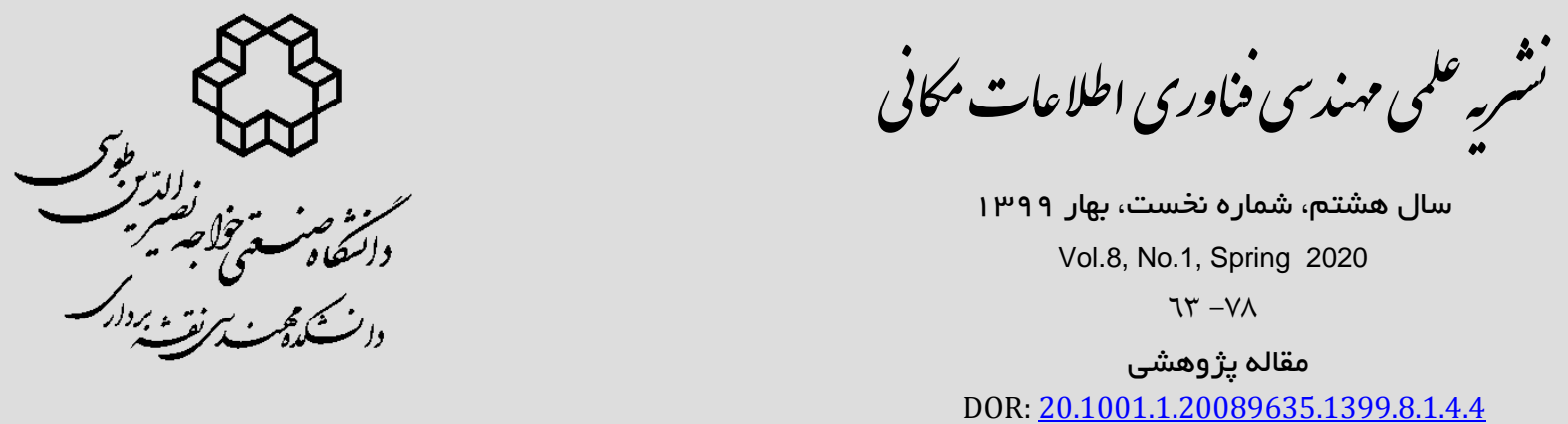

اسيلاين بيضوى و كاربرد آن در توليد دادههاى شتاب ثقل سطح دريا در خليج فارس

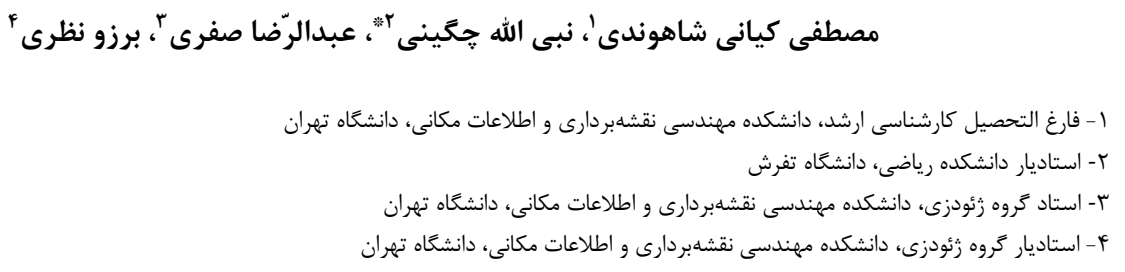

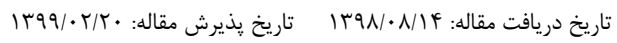

جكيده

در اين مقاله، روش درونيابى براى توليد دادهاى شتاب ثقل در سطح دريا در خليج فارس با استفاده از زئوئيد حاصل از ارتفاعسنجى

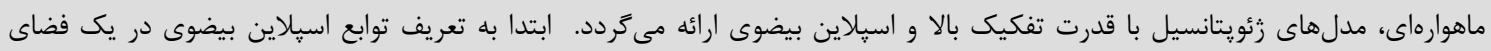

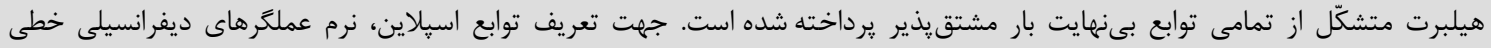

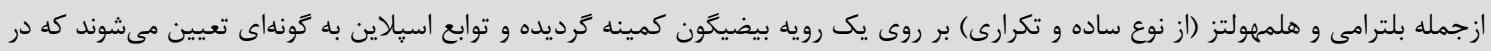

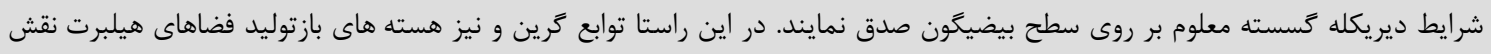

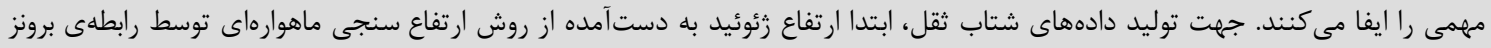

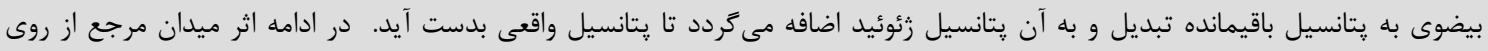

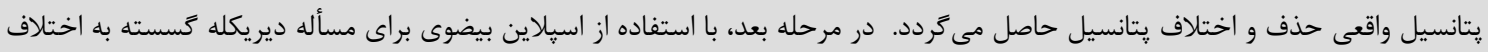

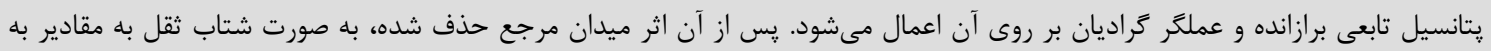

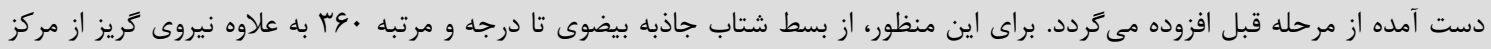

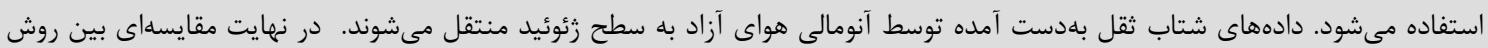
درونيابى اسيلاين بيضوى و كروى ارائه مى مَردد.

كليد وازهها : كمينهسازى نرم عملكر ديفرانسيلى، هسته باز توليد، اسيلاين بيضوى، درون يابى، شتاب ثقل حاصل از عمليات كشتى. 
بيضيكون است كه به اسيلاينهاى بيضوى منجر مى گردد. تعيين اسيلاينهاى روى يك كره قبلا مورد مطالعه قرار كرفته است. يكى از مههمترين تحقيقاتى كه در اسيلاينهاى بيضوى صورت يذيرفته حل مسائل مرتبط در فضاىهاى سوبولف است. در اين مسائل، تابع درونياب اسيلاين بيضوى براى حالت خاصى موسوم به هسته آبل يواسون بيضوى بر اساس سرى نامتناهى از برى برائ

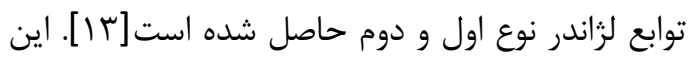
هسته در واقع جواب مسألهى با شرايط دير ديكله كسسته در خارج از رويه بيضيكون براى عملكَ لإِلاس

روش توليد دادهاى شتاب ثقل در سطح دريا با

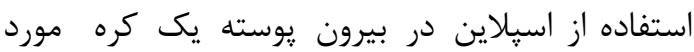

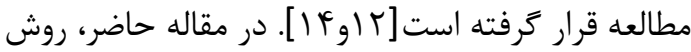
اسيلاين بيضوى با روش اسيلاين كروى مقايسه مى كردد. با توجه به اينكه هندسه ميدان ثقل زمين توسط مختصات بيضوى بهتر مدل مى مَردد، به نظر مىرسد در نظر كرفتن هندسه بيضوى به جاى هندسه

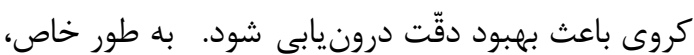
منطقهاى كه دادههاى ثقل در آن توليد مى كردد، خليج فارس است. در اين خصوص، از دادههاى ارتفاعسنجى ماهوارهاى و مدلهاى زئويتانسيل با قدرت تفكيك بالا إنائ استفاده مى گردد. در نهايت با مقايسه نتايج به دست آمده با دادههاى ثقل جمعآورى شده توسط عمليات

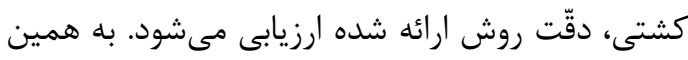

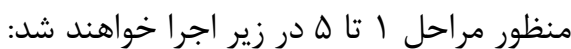

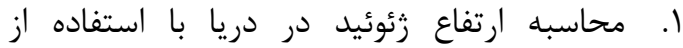

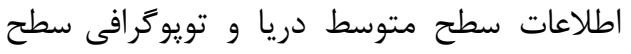
دريا،

r. محاسبه يتانسيل باقيمانده با استفاده از فرمول

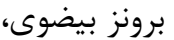

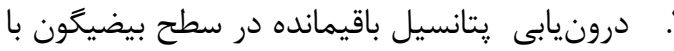

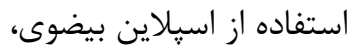

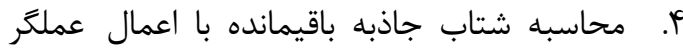
كراديان به تابع يتانسيل باقيمانده مرحله قبل،
| - 1- (- مقدمه

يكى از اهداف مهم در زئودزى و زئوفيزيك، مدل سازى ميدان ثقل زمين است. داده مههم براى مدل-

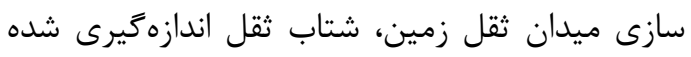

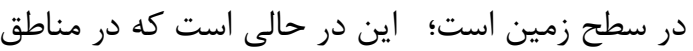
دريايى، به دليل عوامل مختلفى نظير خطاهاى ناشى از

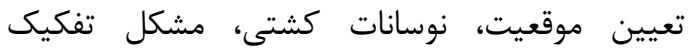
شتابهاى حركت كشتى از شتاب جاذبه و همجنين خطاهاى صفر، كاليبراسيون، ضرايب مقياس و خطاهاى ناشى از دما و رطوبت، شتاب ثقل مشاهده شده از دقت

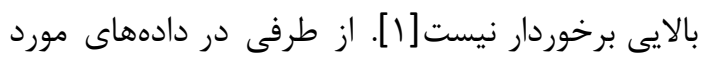

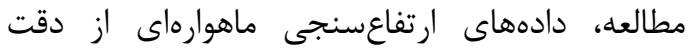

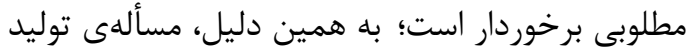

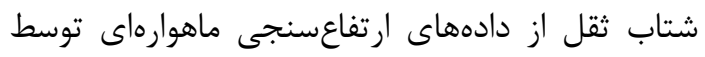

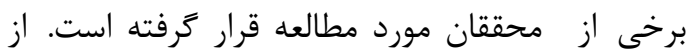
جمله تحقيقات انجامشده در اين مسأله، توليد شتاب

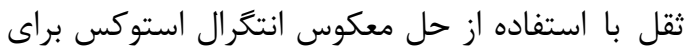

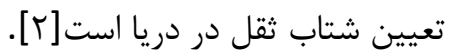
دادههاى ارتفاعسنجى ماهوارهاى براى تعيين آنومالى ثقل به صورت كسترده در زئودزى مورد استفاده قرار مى گيرند. روشهاى متداول در حل حل اين مسأله، عمدتا استفاده از انتكرال استوكس، هوتين و يان ونينگ ماينز است. بدليل هموارى بالاى توابع اسيلاين،

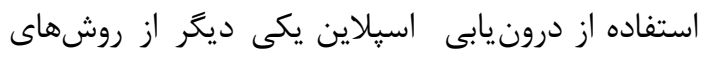

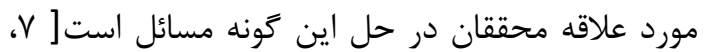

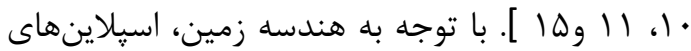
كروى و بيضوى از اهميت ويزهاى برخوردار هستند.

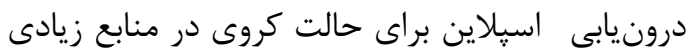

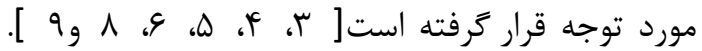

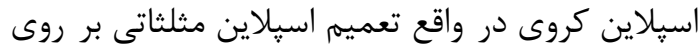
دايره در صفحه است كه بر روى يكى ريك رويه خميده مطرح مى مردد؛ بنابراين بسيارى از خواص اسِيلاين كروى مشابه با حالت دو بعدى آن بر روى دائ دايره است.

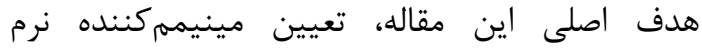
عملكرهاى ديفرانسيلى خاصى بر روى يوسته يك إنى ترين 
فضاى هيلبرت يرداخته مىشود. در بخش ثل، توابع

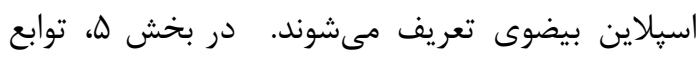
درونياب اسيلاين بيضوى براى حل مسئله توليد داده-

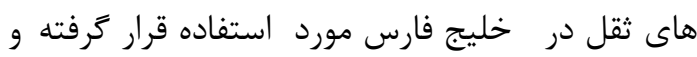

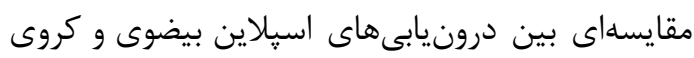
انجام خواهد شد. در بخش و، نتايج اين تحقيق ارائه

خواهد شد.

\section{r- تعاريف و مفاهيم اوليه}

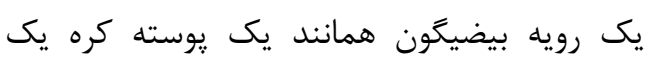

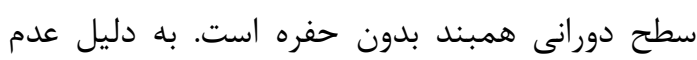
تساوى قطرهاى اطول و اقصر رويه بيضيكون، اين رويه

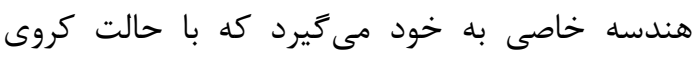

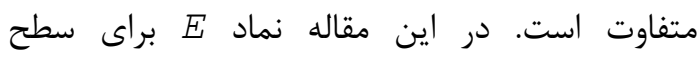
بيضيكون استفاده مى شود. سيستم مختصاتى كه در

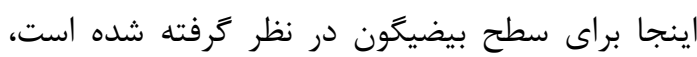

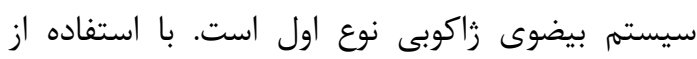

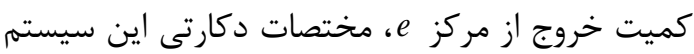

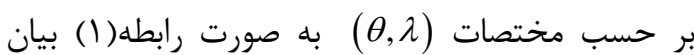
مى شود.

در اين مقاله مهمترين عملكر ديفرانسيلى كه مورد استفاده قرار كرفته و ساير عملكرها به كمك آن قابل

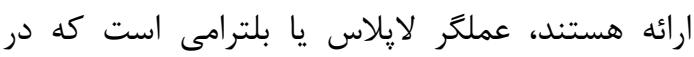

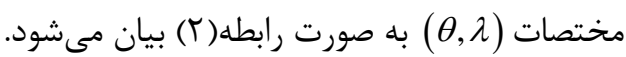

$(x, y, z)=\left(a \sin \theta \cos \lambda, a \sin \theta \sin \lambda, a \sqrt{1-e^{2}} \cos \theta\right)$
ه. بازكرداندن اثرات حذف شده به منظور محاسبه شتاب ثقل در سطح دريا.

اكر دادههاى مسأله بر روى بخشى از دريال رويه يك

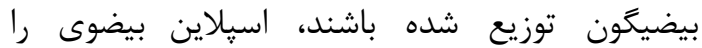

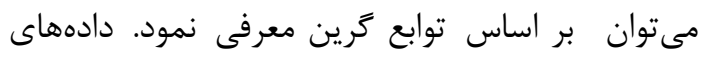
مسأله ممكن است مقدار تابع در نقاط خاصى از روئ دان بيضيگون و يا مشتق تابع در راستاى بردار نرمال رويه بيضيكون در نقاط تعيين شده باشد. در مقاله حاضر از

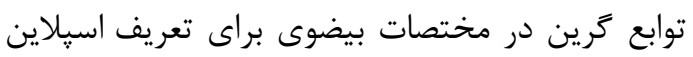
بيضوى و درونيابى دادههاى شتاب ثقل استفاده مى دي دري

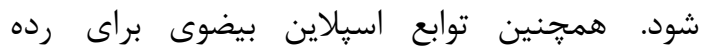
وسيعترى از عملكرهاى ديفرانسيلى خطى محاسبه شده و نتايج بدست آمده براى توليد دادههاى شتاب

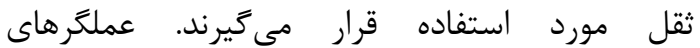
ديفرانسيلى مورد بحث در اين مقاله، عملكَهاى ديفرانسيلى بلترامى و هلمهولتز (از نوع ساده و تكرارى) بر روى يك سطح بيضيكون هستند.

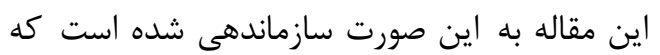

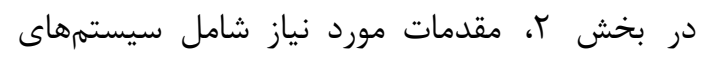
مختصات، عملكَهاى مورد استفاده براى حل مسئله اسيلاين بيضوى و فضاى هيلبرت هسته بازتوليد مطرح

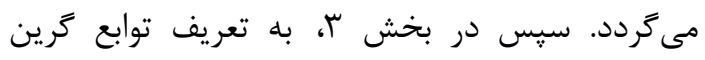
يرداخته مىشود. توابع گرين نظير عملكر بلترامى و تكرارهاى آن و نيز عملكَ هلمهولتز تكرارى محاسبه مى كردند. در ادامه اين بخش به تعريف هسته بازتوليد رابطه (1) $\Delta_{B}=\frac{1}{a^{2}\left(1-e^{2} \sin ^{2} \theta\right)} \frac{\partial^{2}}{\partial \theta^{2}}+\frac{\cot \theta}{a^{2}\left(1-e^{2} \sin ^{2} \theta\right)^{2}} \frac{\partial}{\partial \theta}+\frac{1}{a^{2} \sin ^{2} \theta} \frac{\partial^{2}}{\partial \lambda^{2}}$ رابطه (T)

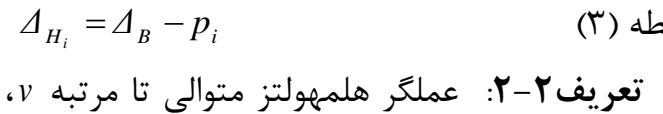
تركيب متوالى عملكر هلمهولتز است كه به صورت

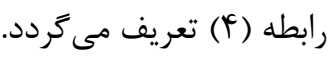
$\Delta_{H_{C}}=\Delta_{H_{0}} \ldots \Delta_{H_{v}}$
(i) (i) (i)

در ادامه به تعريف ساير عملكرهاى مورد نياز مى تيردازيم. تعريف ا - 1 : عملكر هلمهولتز از مرتبه iا، به

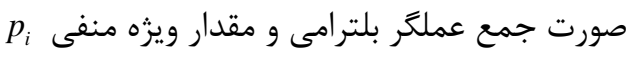
نظير آن است كه در رابطه (؟آ) آورده شده است 
باشد. به بيان ديكر اسيلاين بيضوى جواب يكتاى مسأله

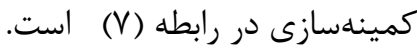

$S=\operatorname{argmin}_{f \in \mathcal{H}(\mathrm{E})} \square \Delta_{B}^{v} f \square_{L^{2}(\mathrm{E})}$

(V) رابطه

با توجه به ماهيت مسأله درونيابى، تابع S

تعيين مى كردد كه در رابطه (V) صدق نموده و به ازاى مجموعه D D كسسته رابطه (N) برقرار باشد.

$S\left(\eta_{i}\right)=U_{i} \in \mathbb{R}, i=1, \ldots, J$

رابطه (1)

توضيحr-r: اگر نرم در فضاى (E) تعريف گردد، آنگاه نرم يك $\square f \square_{H(\mathrm{E})}=\square \Delta_{B}^{v} f \square_{L^{2}(\mathrm{E})}$ تابع ثابت غير صفر برابر صفر مى شود. در اين حالت

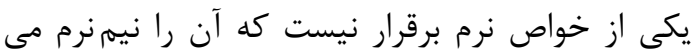

توضيح r-r": با توجه به خواص نيهنرم در فضاهاى

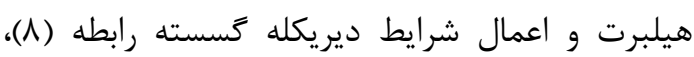

وجود و يكتايى جواب مسأله كمينهسازى رابطه (V)

تضمين مى كردد [ع 19] .

ץ- مسأله كمينهسازى نرم عملكَر بلترامى در سطح بيضيگون

در تعيين هسته بازتوليد فضاى هيلبرت روشهاى كوناگونى از جمله روش توابع گَرين وجود دارد كه در

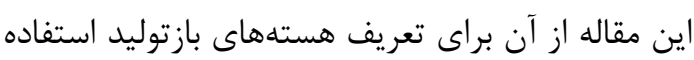

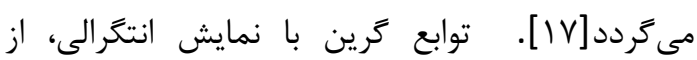

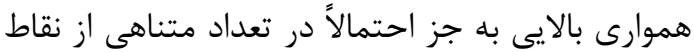

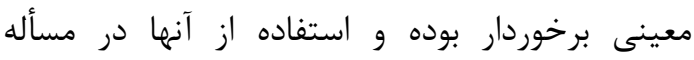
درونيابى بسيار مناسب است. به كمك اتحاد كرين، تابع كرين G در رابطه (9) صدق مى كند. $\iint_{Q} G \mathcal{L}^{v} F d Q=B . T .+\iint_{Q} F \mathcal{L}^{v} G d Q$

(9)

كه در آن L ل يكى عملكَ ديفرانسيلى خطى از مرتبه دوم، F تابعى $2 v$ بار مشتقيذير و.B.T شرايط كرانهاى روى دامنه Q است.

رابطه (•() پس از انجام عمليات لازم بر روى

رابطه (9) به ازاى =1 v v حاصل مى شود [ T ] ].
كه در آن عملكَر ديفرانسيلى با بالاترين درجه مشتقات جزئى از مرتبه v2 است انس

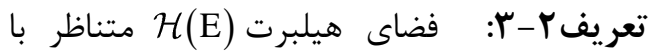
عملكر L در قالب عملكَرهاى روابط (Y)- (I)، متشكل

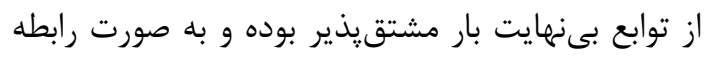
(b) تعريف مىشود.

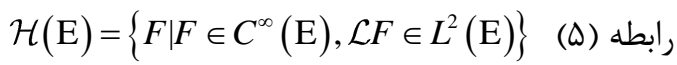
توضيحr-I: با توجه به نظريه توزيعها در آناليز تابعى، تابع F در رابطه (ه) يك توزيع است و بنابراين

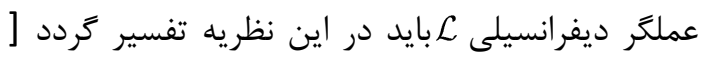

فضاى (E) أر از اهميت زيادى در تعريف هسته بازتوليد

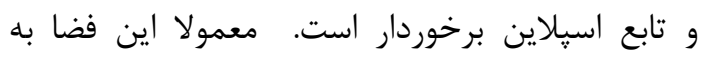
صورت رابطه (9) تجزيه مى رَردد. $\mathcal{H}(\mathrm{E})=\mathcal{H}_{0}(\mathrm{E}) \oplus \aleph_{\mathcal{L}}$ رابطه (9)

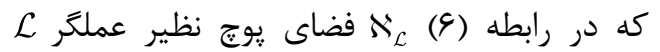
است. براى تعريف توابع اسيلاين بيضوى بر اسلهای

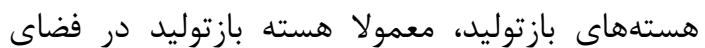
تع H $\mathcal{H}_{0}(\mathrm{E})$ اسيلاين تعريف مى

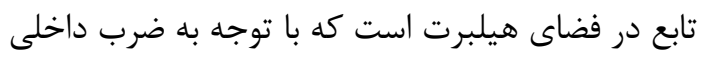
در آن فضا مىتوان فضاى هيلبرت مورد نظر را بازسازى دي كرد. معيارى كه براى انتخاب درونياب بهينه اتخاذ

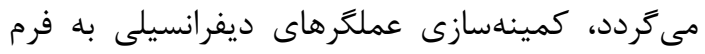
روابط (T)- (I) است[ [IV] [IV . توجيه فيزيكى اين روش، كمينهسازى انرزى خمش يك يوسته بيضيكون است

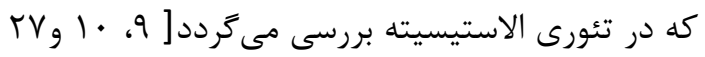

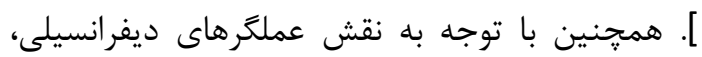
اين معيار به انتخاب تابع درونياب با هموارى بيشينه منجر مىشود.

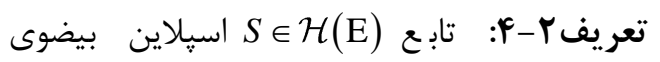
ناميده مىشود هر كاه جواب مسأله كمينهسازى عملكر تأر بلترامى تكرارى 


$$
\iint_{E} G \Delta_{B} F d E=\left.\int_{0}^{\pi} \frac{\sqrt{1-e^{2} \sin ^{2} \theta}}{\sin \theta}\left(G \frac{\partial F}{\partial \lambda}-F \frac{\partial G}{\partial \lambda}\right)\right|_{0} ^{2 \pi} d \theta+\iint_{E} F \Delta_{B} G d E \quad \text { (1) }
$$

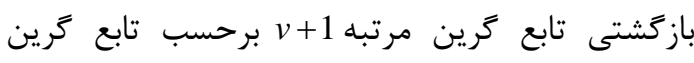
مرتبه v به صورت رابطه (rار) است. $G_{v+1}(\xi, \eta)=\iint_{E} G_{v}(\xi, \zeta) G_{v}(\zeta, \eta) d \zeta(\mid r)$ رابط به كمك بسط مقادير ويزه، ضابطه تابع كرين

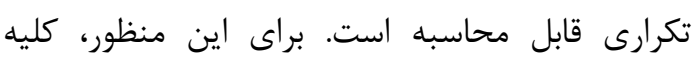

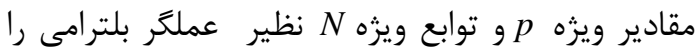
جنان بيابيم كه در رابطه (f) ( ) صدق نمايند. $\left(\Delta_{B}-p\right) N(\xi)=0$

رابطه (if) با توجه به ويوست شمارهA مرجع [ 19] ، ثابت مىشو د K $K_{n m}(\xi)$

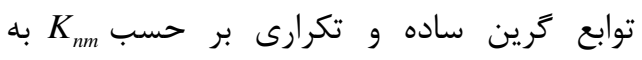
صورت رابطه (ه) ) تعريف مى كىردد [19] . $G_{v}(\xi, \eta)=\sum_{k=1}^{\infty} \sum_{m=-k}^{+k} \frac{K_{k m}(\xi) K_{k m}(\eta)}{(-k(k+1))^{v}} \quad$ (ابطه (1)

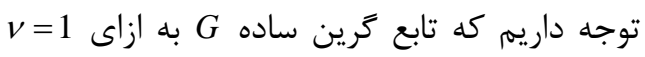
از رابطه (ه ا) ) حاصل مى شود.

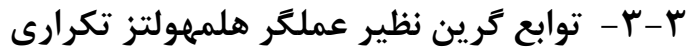
اخر عملكر L داراى رابطه (\$) باشد، تابع كرين

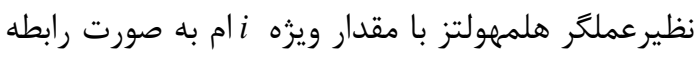

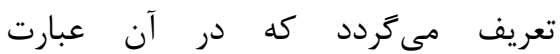
$\sum_{m=-i}^{+i} K_{i m}(\xi) K_{i m}(\eta)$ هلمهولتز است. جهت تعيين جواب يكتا، اين هسته به سمت راست معادلهى تابع گرين نظير شرايط ديريكله

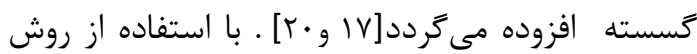

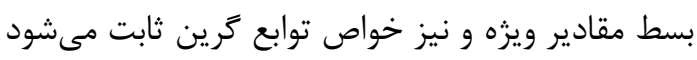

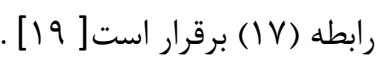

همانطور كه بيان شد رويه بيضيكون يك سطح

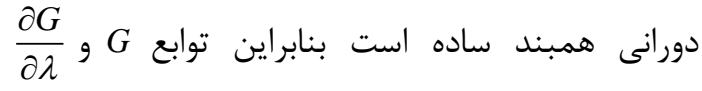
نسبت ג به متناوب مى باشند و در نتيجه رابطه (11)

$$
\iint_{E} G \Delta_{B} F d E=\iint_{E} F \Delta_{B} G d E \text { رابطه (1) }
$$

همجنين به راحتى ثابت مى شود كه رابطه (11) براى عملكر

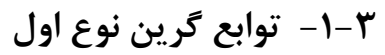

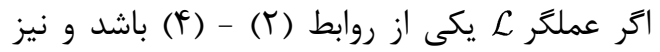
ه

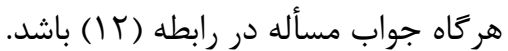

$$
\text { رابطه (I ) }
$$

در رابطه (ז ())، $\delta$ نماد تابع دلتاى ديراى است.

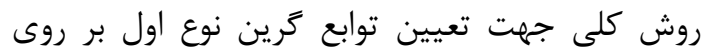

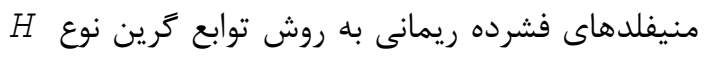

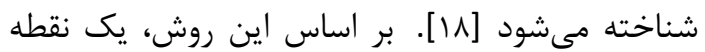
تكين مانند يك ولتاز، بر روى قطبهاى بيضيكون قرار $\theta=0, \pi$

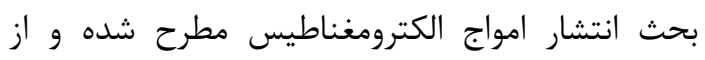

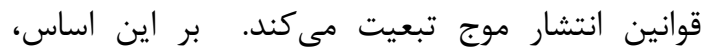

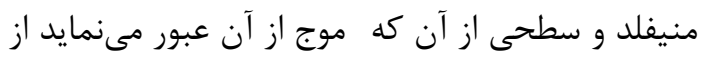

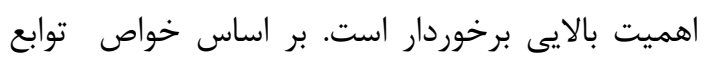
كرين نوع اول، اين تابع و مشتق آن در هر نقطه به جز قطبها و = =

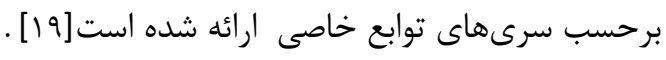
r-r- توابع كرين تكرارى حال به تعيين تابع كرين تكرارى مى يردازيم كه در

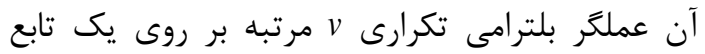

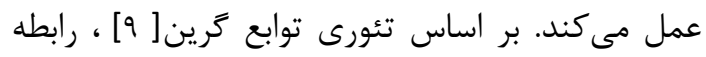




$$
\begin{aligned}
& (\mathcal{L}+i(i+1)) G_{H}^{i}(\xi, \eta)=\delta(\xi-\eta)-\sum_{m=-i}^{+i} K_{i m}(\xi) K_{i m}(\eta) \\
& G_{H_{\nu}}^{i}(\xi, \eta)=\sum_{k=1, k \neq i}^{\infty} \sum_{m=-k}^{+k} \frac{K_{k m}(\xi) K_{k m}(\eta)}{(i(i+1)-k(k+1))^{v}}, v=1,2, \cdots
\end{aligned}
$$

كه در يك نقطه كَراى داراى مقدار واحد و در ساير نقاط كرهاى مقدار صفر را اتخاذ مى كنند.

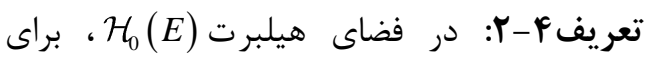
هسته بازتوليد مسألهى با شرايط ديريكله كسسته با سيستم يكتا حلشونده ( $)$ (19) تعريف مى كردد.

تابع اسيلاين بيضوى نظير مسأله مورد مطالعه اين

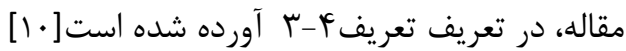

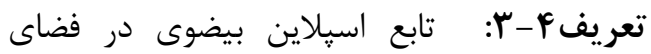

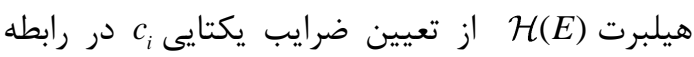
(T·) از طريق حل سيستم معادلات حاصل از دادههاى ديريكله گسسته روى سطح بيضيكون E تعيين

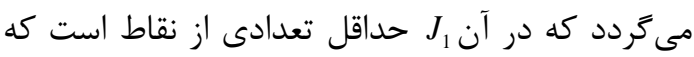
يك سيستم קذيرفتنى تشكيل مى مهند ماتريس كرنل تشكيل شده با اين نقاط وارونيذير است.

$$
\begin{aligned}
& \text { F - توابع اسيلاين بيضوى }
\end{aligned}
$$

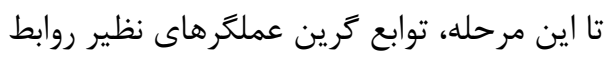

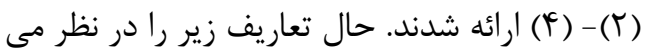

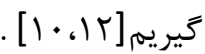

$$
\begin{aligned}
& \text { تعريف F-1: به ازاى مجموعه يذيرفتنى } \\
& \text { لإئ } \\
& B_{k}\left(\eta_{i}\right)=\delta_{k i}, \quad k, i=1, \ldots, J
\end{aligned}
$$

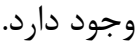$$
\text { توضيح F-1: توابع پايهاى لاكرانز از اهميت بالايى }
$$

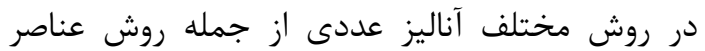

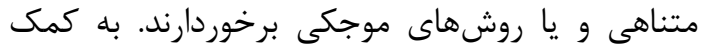

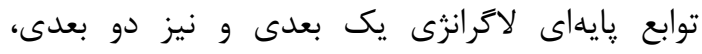
موجكهاى يك بعدى و دوبعدى معرفى مى كرى بردند

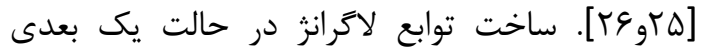
بسيار ساده است. اين توابع جندجملهاىهايى هستند $\mathbf{K}_{H_{0}(\mathrm{E})}(\xi, \eta)=G_{v}(\xi, \eta)-\sum_{j=1}^{M} G_{v}\left(\xi, \eta_{j}\right) B_{j}(\eta)+\sum_{j=1}^{M} G_{v}\left(\eta, \eta_{j}\right) B_{j}(\xi)+$

$$
\sum_{j=1}^{M} \sum_{i=1}^{M} G_{v}\left(\eta_{j}, \eta_{i}\right) B_{j}(\xi) B_{i}(\eta)
$$

$$
S(\xi)=\sum_{j=1}^{J_{1}} c_{j} B_{j}(\xi)+\sum_{j=J_{1}+1}^{J} \mathbf{K}_{\mathcal{H}_{0}(\mathrm{E})}\left(\xi, \eta_{j}\right)
$$

تعريف F-F تابع اسيلاين بيضوى براى عملكر

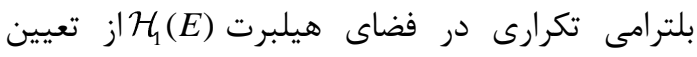
ضرايب يكتايى

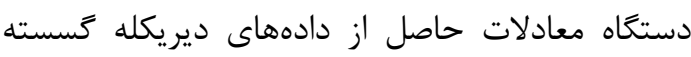
روى E تعيين مىشود.

$$
S(\xi)=\sum_{j=1}^{J} c_{j} G_{v}\left(\xi, \eta_{j}\right) \quad \text { (TI) }
$$

توضيحץ-F

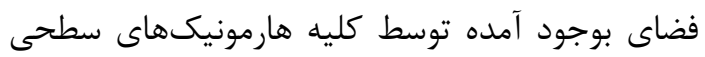

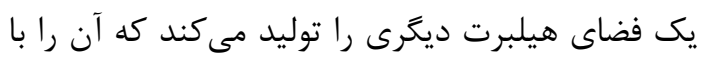
اسيلار

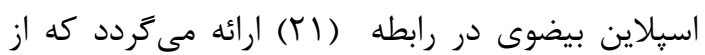
لحاظ كاربردى نسبت به رابطه (•r) مفيدتر است. 
كام ا: تعيين ارتفاع زئوئيد در دريا محاسبه شده از طريق جمع مقادير تويوگرافى سطح دريا و سطح متوسط دريا حاصل از ارتفاع سنجى ماهوارهاى.

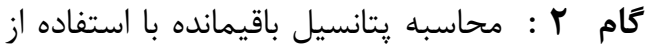

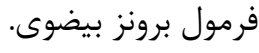

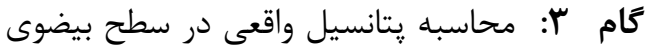

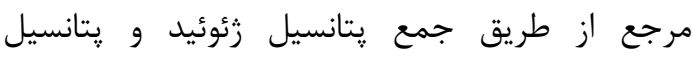
باقيمانده حاصل از كام كا.

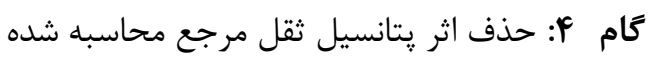

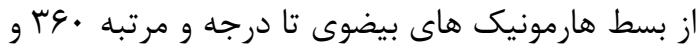

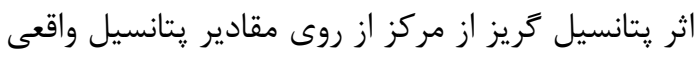
در مرحله بr.

كام ه: درون يابى اختلاف يتانسيل حاصل از

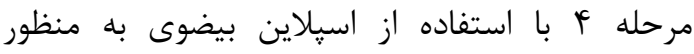

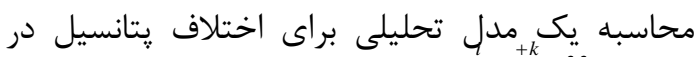

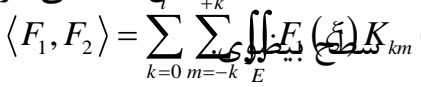
گَام 9: اعمال عملكر گراديان بر روى تابع درون ياب حاصل از مرحله ه جهت تعيين مقادير شتاب ثقل

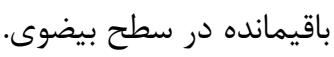

كام لا: بازَرداندن اثر شتاب ثقل مرجع حاصل از بسط هارمونيك هاى بيضوى تا درجه و مرتبه • عب و كريز از مركز در سطح بيضوى مرجع. كام 1: انتقال شتاب ثقل محاسبه شده با محاسبه

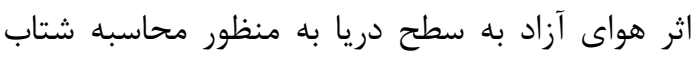
ثقل واقعى در سطح دريا. براى محاسبه زئوئيد در خليج فارس از اطلاعات

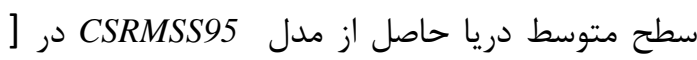

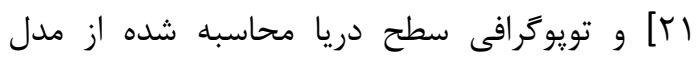
POCM-4B در [Tr] استفاده شدهاست. شكل) (1) نشاندهنده تغييرات سطح متوسط دريا در رليج

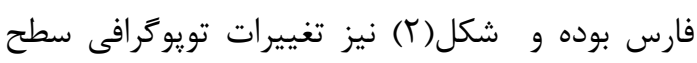
دريا را در منطقه نشان مىدهد. توضيح+א-r: با توجه به اينكه اسيلاين بيضوى تعميم اسيلاين مثلثاتى در صفحه است، بنابراين رده مهمى از توابع اسيلاين به نام اسيلاينهاى طبيعى نيز قابل تعريف بر روى سطح بيضيكون E هستند. تعريف F-ه: اسيلاين بيضوى تعريفشده در رابطه

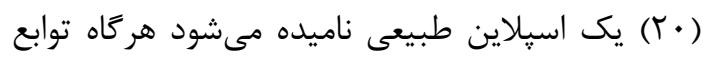
هسته آن در رابطه (Tr) صدق كنند. رابطه (Tr) (ن) $\sum_{j=1}^{J} c_{j} K_{k m}\left(\xi_{j}\right)=0, k=0, \ldots, i ; m=-k, \ldots,+k$ توضيحf-F

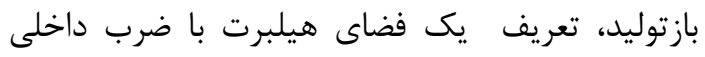

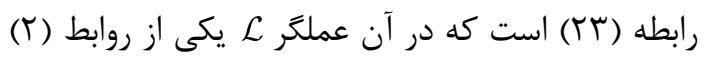

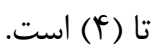

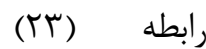
$(\xi) d \xi \iint_{E} F_{2}(\xi) K_{k m}(\xi) d \xi+\iint_{E}\left(\mathcal{L} F_{1}(\xi)\right)\left(\mathcal{L} F_{2}(\xi)\right) d \xi$ هـ - مطالعه موردى: توليد دادههاى شتاب ثقل در خليج فارس با استفاده از اسيلاين بيضوى موردي

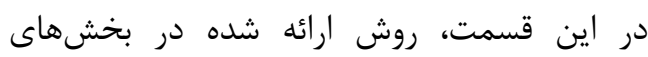
بيشين براى توليد دادههاى شتاب ثقل در خليج فارس

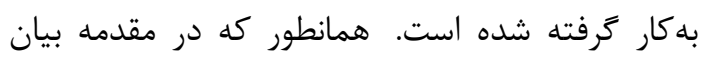

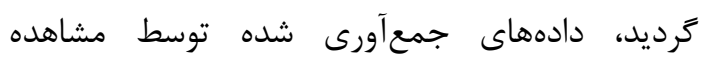
مستقيم شتاب ثقل بر سطح دريا به خطاهاى مختلفى آنى

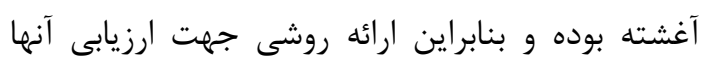

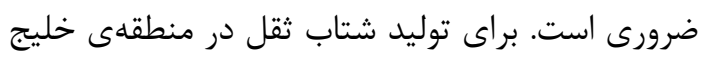

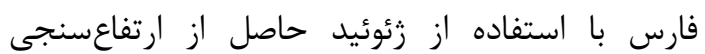
ماهوارهاى، ابتدا زئوئيد در ز خليج فائ فارس محاسبه

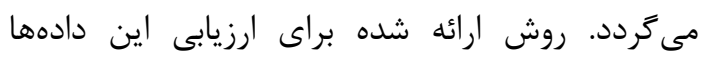

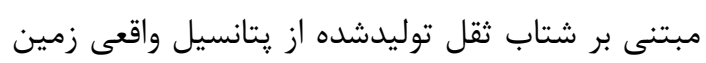

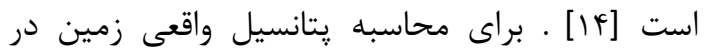
خليج فارس از زئوئيد محاسبه شده در اين منطقه

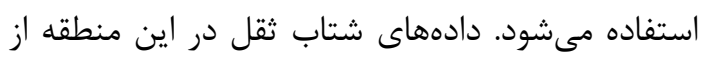
اجراى كام هاى ا تا 1 توليد مى شوند. 


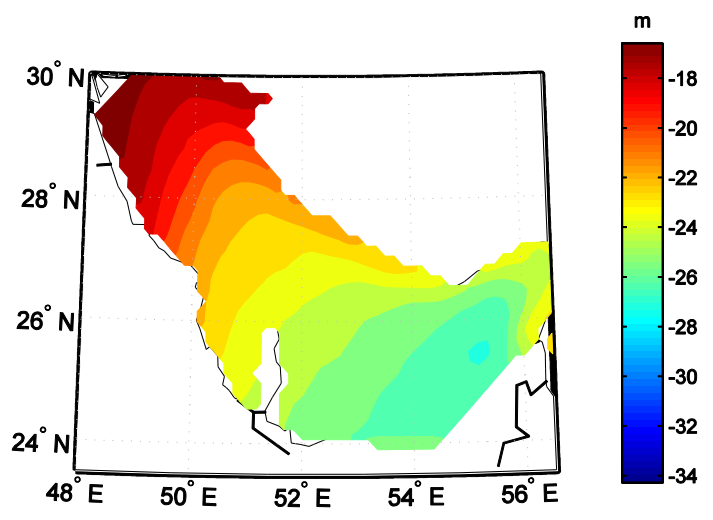

شكل ا: سطح متوسّط دريا در خليج فارس با استفاده از مدل 21] CSRMSS95]

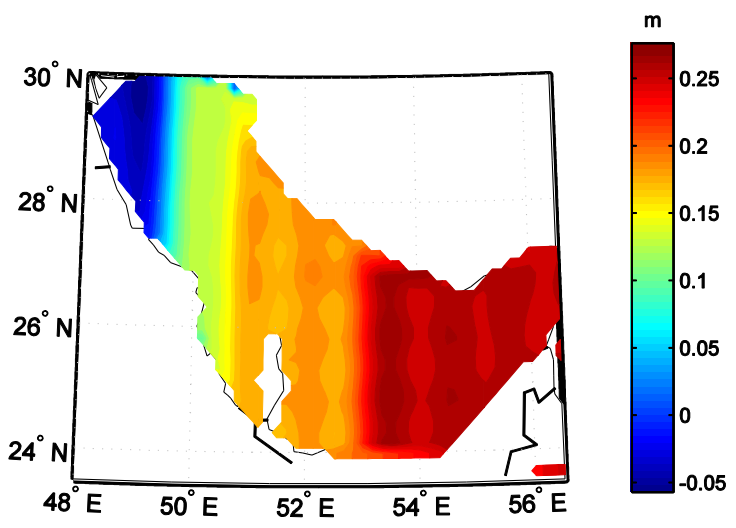

شكل ז: تويوكرافى سطح دريا در خليج فارس با استفاده از مدل 22] POCM-4B]

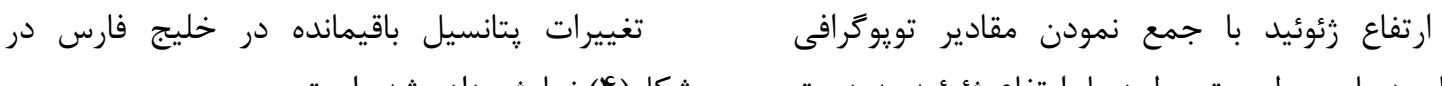
سطح دريا و سطح متوسط دريا، ارتفاع زئوئيد به دست

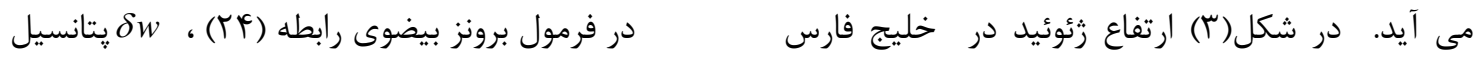

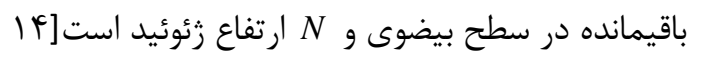
نشان داده شده است. $\delta w=\frac{\frac{G M}{b^{2}+E^{2}}\left(3 \cos ^{2} \phi+1\right) \frac{6 b\left(b^{2}+E^{2}\right) \cot ^{-1}\left(\frac{b}{e}\right)-3 b E+E^{2}-3 E}{6 b\left(b^{2}+E^{2}\right) \cot ^{-1}\left(\frac{b}{E}\right)-3 b E}+\omega^{2} b \sin \phi}{\sqrt{\frac{b^{2}+E^{2} \cos ^{2} \phi}{b^{2}+E^{2}}}} N$ 

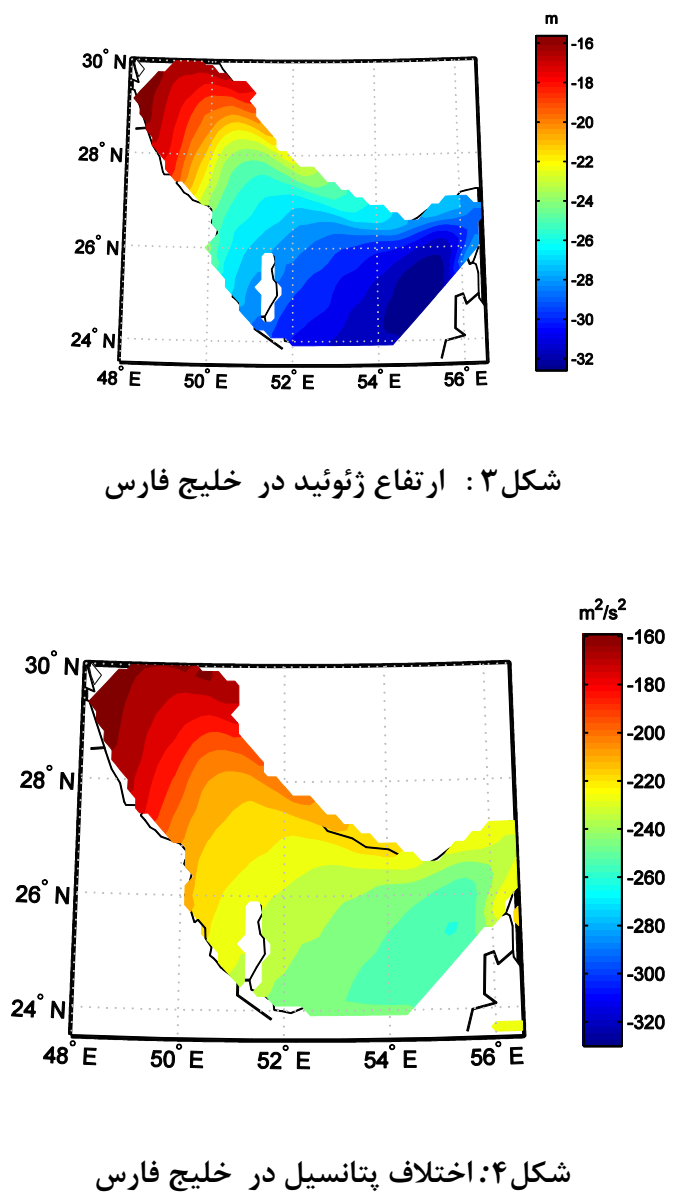

به منظور محاسبه يتانسيل ثقل واقعى در سطح تردد. تغييرات پتانسيل ثقل واقعى در سطح بيضوى در

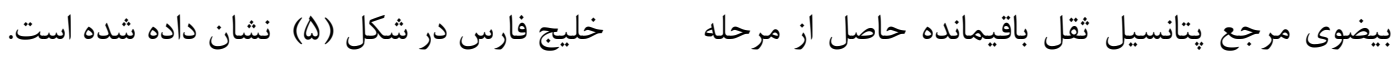
قبل به يتانسيل زئوئيد

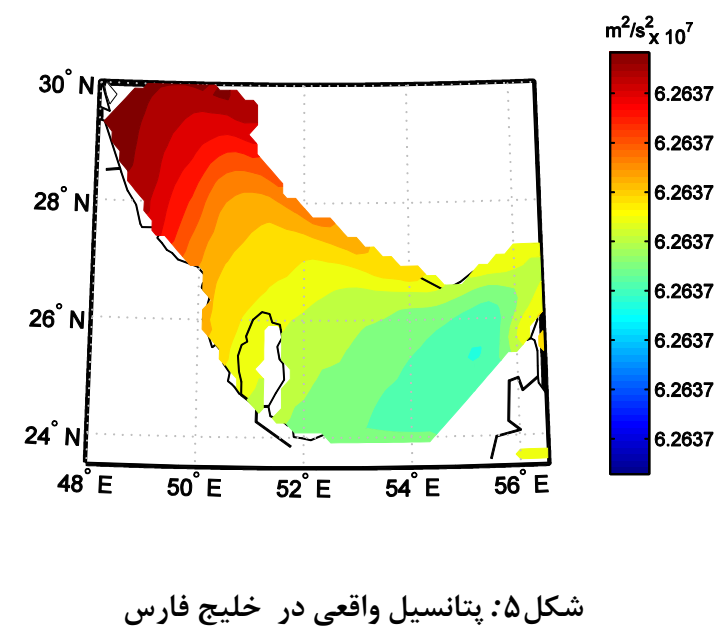




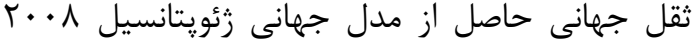

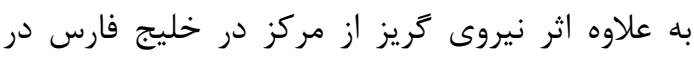

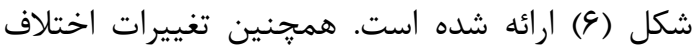
يتانسيل dW در خليج فارس در شكل (V) نشان داده شده است.
به منظور محاسبه اختلاف يتانسيل dW در سطح

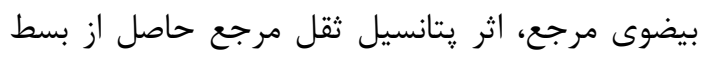

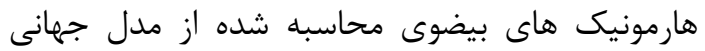

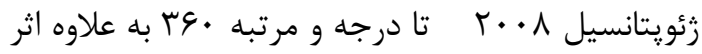
نيروى كريز از مركز حذف مى مردد. تغييرات يتانسيل

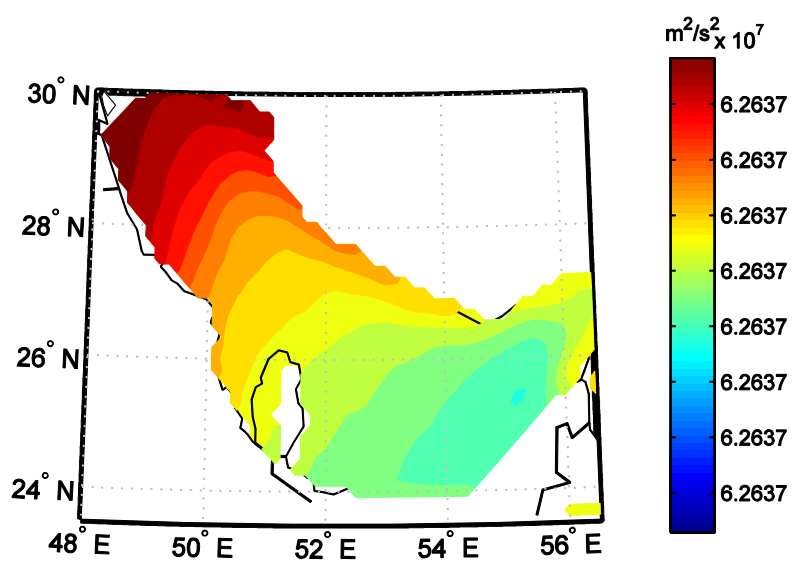

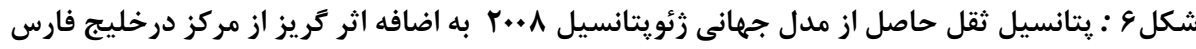

هموارسازى در درونيابى هيبريد مىتوان از روش

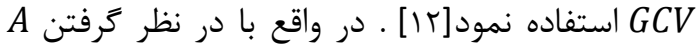

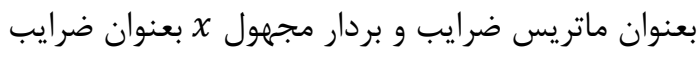

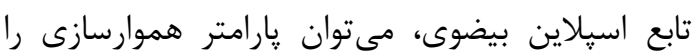

$$
\text { از }
$$

در شكل (^)، نمودار GCV نمايش داده شده

در گام بعد با اعمال عملكر گراديان بر روى تابع اختلاف ريانسيل مرحله قبل، شتاب جاذبه باقيمانده از باز

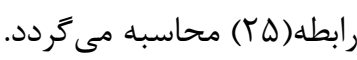
$\delta g=\nabla d W$ رابطه (T)
با داشتن اختلاف يتانسيل dW در سطح بيضيكون

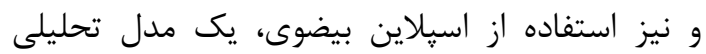

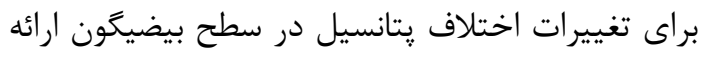
مى كردد. توجه به ماهيت تابع يتانسيل ثقل باقيمانده،

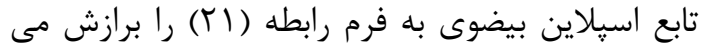

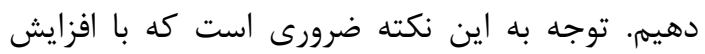

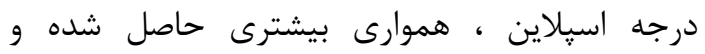

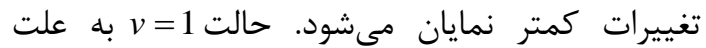
نايِيوستگى تابع گرين قابل استفاده نيست. لذا به ازاى

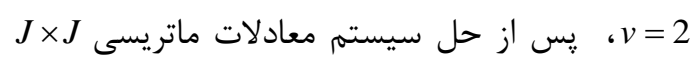

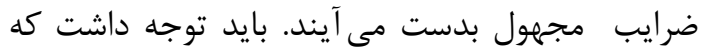
بدليل وجود نويز در داده ها، درونيابى از نوع هيبريد

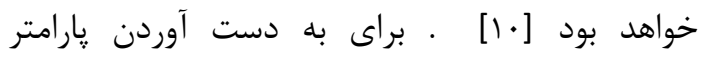




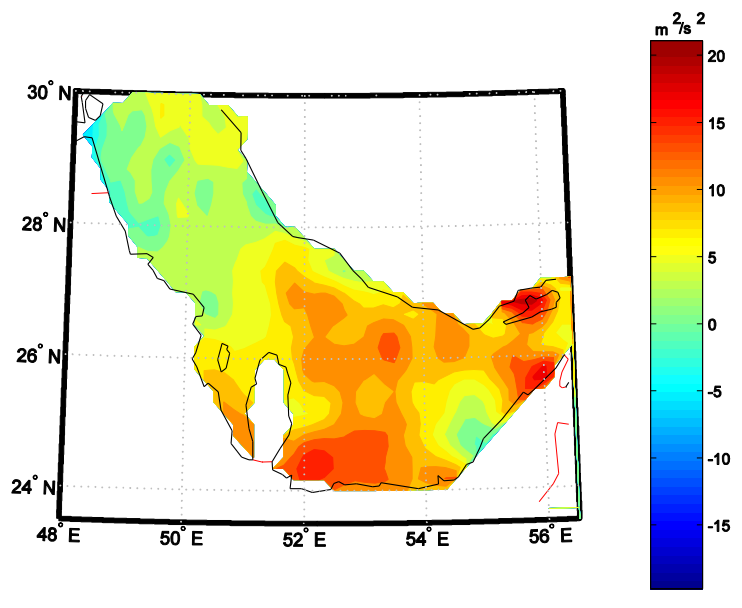

شكل V : يتانسيل باقيمانده در خليج فارس

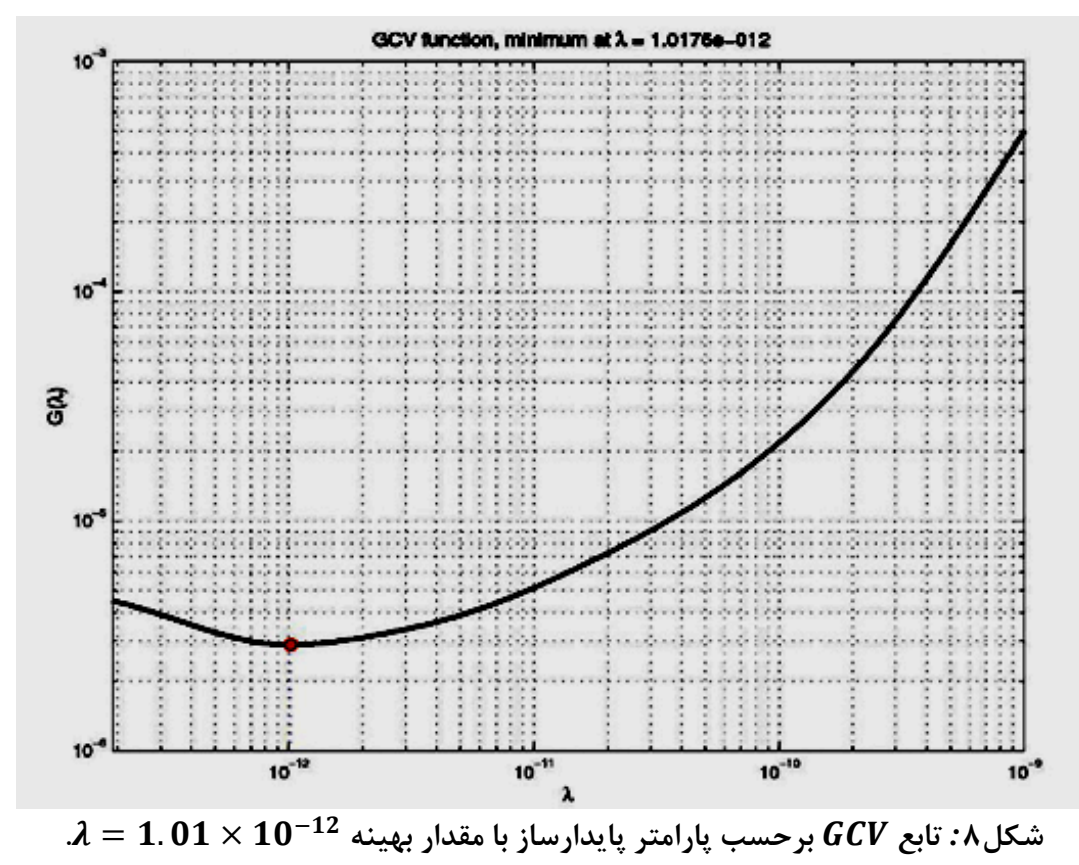

با توجه به اينكه درخليجفارس ارتفاع زئوئيد منفى

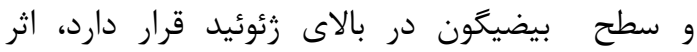

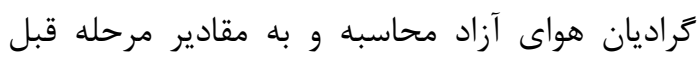

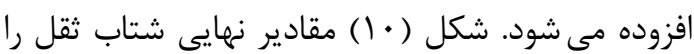
كه از روش ذكر شده به دست آمده است نشان مى مي دهد.
در شكل(9) تغييرات مقادير g

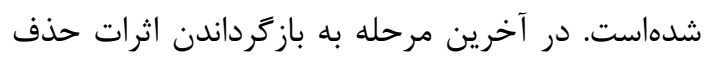
شده به منظور محاسبه شتاب ثقل در سطح دريا مىيردازيم. براى اين منظور اثر شتاب ثقل مرجع حاصل از بسط هارمونيكهاى بيضوى تا درجه و مرتبه

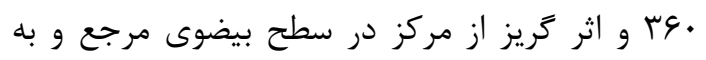
شتاب جاذبه باقيمانده مرحله قبل اضافه مىشود. 
جهت مقايسه مقادير حاصل از مدلسازى و مقادير يابى اسيلاين مقايسه مىنماييهم. دادهایى مشاهده شده

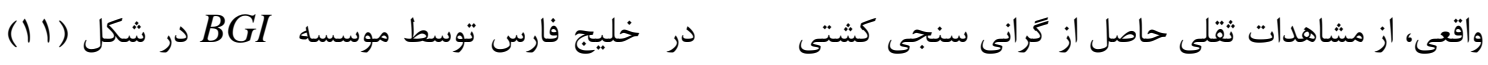

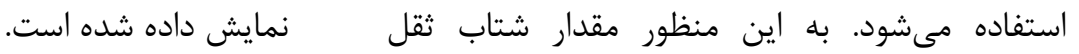

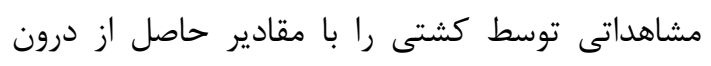

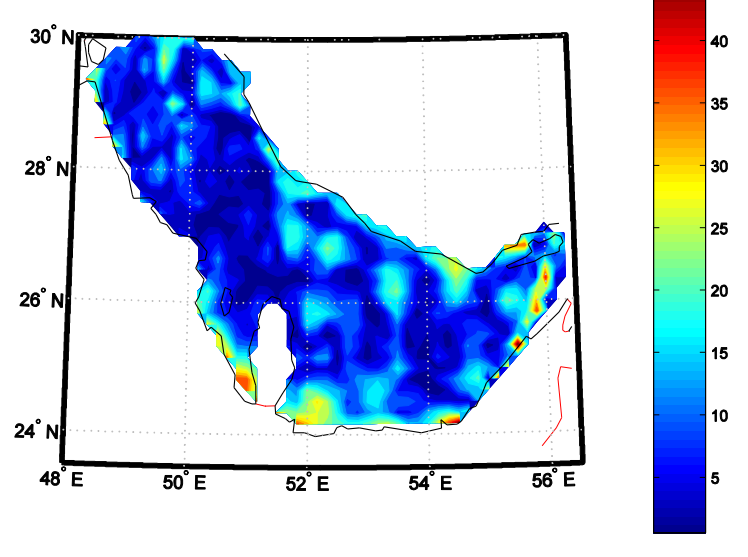

شكل9 : مقادير شتاب ثقل باقيمانده $\delta$ در خليج فارس

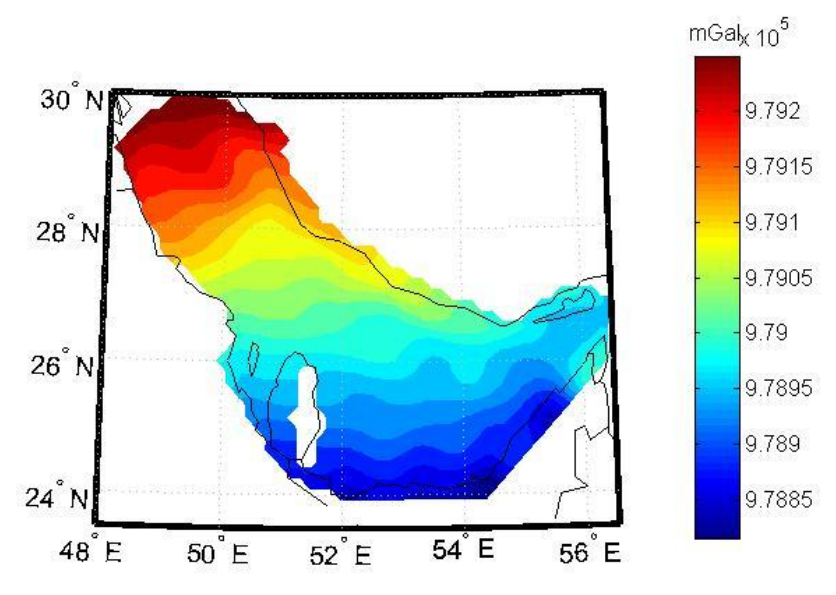

شكل •1 : مقادير شتاب ثقل در خليج فارس حاصل از درون يابى اسيلاين بيضوى 


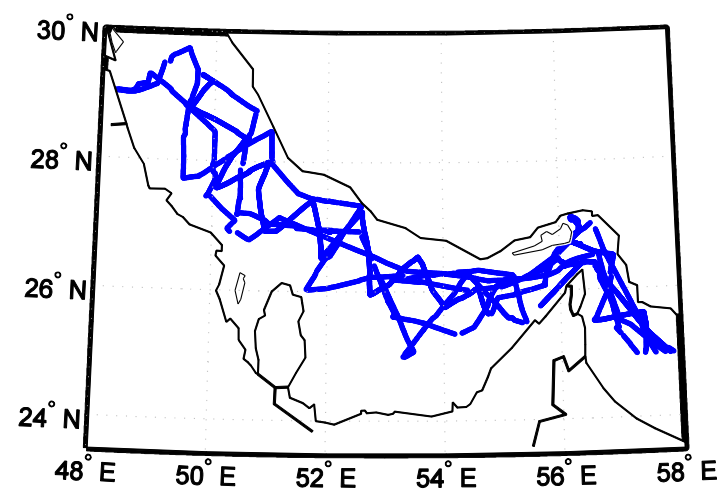

شكل ||: دادهاى مشاهده شده كرانى سنجى كشتى توسط موسسه BGI

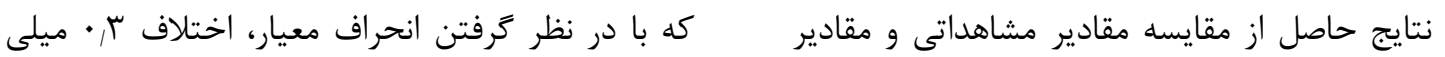

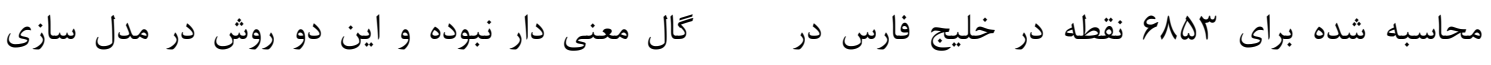

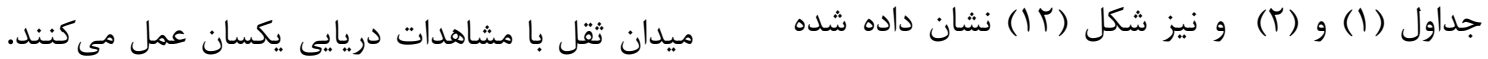

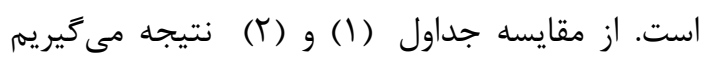

جدول ا: مقايسه مقادير حاصل از مشاهدات و مقادير محاسبه شده توسط اسيلاين بيضوى (بر حسب ميلى $ا ل) ~$

\begin{tabular}{|c|c|c|c|}
\hline انحراف معيار & ميانغين & حداكثر & حداقل \\
\hline $11 / \mu a r$ & -11/9V & $\Delta, Y G \varphi$ & $-r \cdot \lambda V V$ \\
\hline
\end{tabular}

جدول : مقايسه مقادير به دست آمده از مشاهدات و مقادير محاسبه شده توسط اسيلاين كروى (بر حسب ميلىكال)

\begin{tabular}{|c|c|c|c|}
\hline حداقل & حداكثر & \\
\hline $11 / 1 \% 9$ & $-r \cdot / \Lambda \Lambda$ & $\Delta, r 99$ & $-r \cdot \Lambda \vee \Lambda$ \\
\hline
\end{tabular}




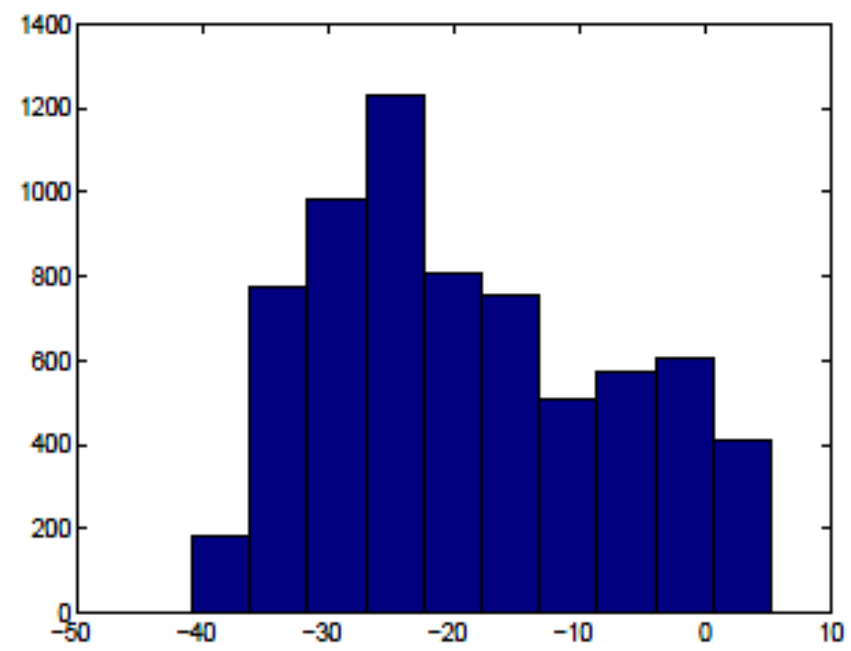

شكل rا : نمودار مستطيلى توزيع اختلاف دادههاى مشاهداتى و محاسباتى. (محور عمودى تعداد تكرار و محور افقى مقدار تفاوت بر حسب ميلى گال است.)

بيضوى به يتانسيل باقيمانده تبديل زرديد. با جمع نمودن زتانسيل زئوئيد و رتانسيل باقيمانده، يتانسيل واقعى به دست آمد. در مرحله سوم، يس از حذف اثر

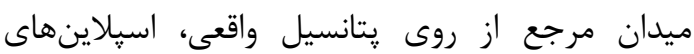
بيضوى و كروى طبيعى به اين دادهها برازش داده شدي. در مرحله جهارم، از توابع به دست آمده در مرحله سوم

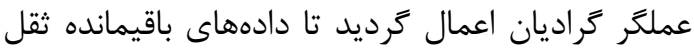

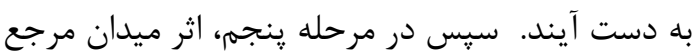
از طريق ضرايب هارمونيكهاى بيضوى بازگردانده شد.

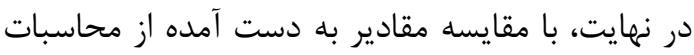
و مشاهدات ثقل جمع آورى شده توسط كشتى، ميزان انطباق مقادير محاسباتى و مشاهداتى واقعى بررسى كرديد. همجنين با مقايسه اسيلاينهاى بيضوى و كروى، مشخص گرديد كه تفاوت معنى دارى بـ بين اسييلاين بيضوى و كروى نبوده و اين دو درون ياب در مر مردي

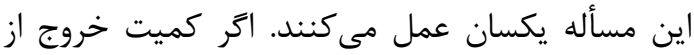
مركز صفر اتخاذ گردد آنگاه كليه روابط اسيلاين كروى مرى

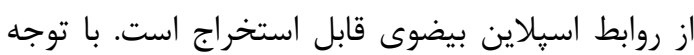
به اينكه شتاب ثقل مشاهده شده در يك منطقه نسبتا كو جك دريايى مورد بررسى قرار گرفته است در نتيجه تفاوت محسوسى مشاهده نمى گردد. از سوى ديخر عدم تفاوت اسيلاينهاى كروى و بيضوى در منطقه مذكور،

$$
\text { 9- نتيجه گيرى }
$$

در اين مقاله تئورى درون يابى اسيلاين بيضوى

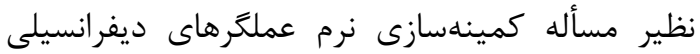
خطى از قبيل بلترامى و هلمهولتز با شرايط ديريكله گسسته بر روى يك سطح بيضيگون مورد مطالعه قرار كرفتهاند. بر اساس اين كمينهسازى در فضاى هيلبرت متشكل از توزيع هاى از هر مرتبه مشتقيذير، هستههاى بازتوليد به كمك روش توابع گرين محاسبه شدند. به كمك توابع يايهى متعامد يكه، توابع اسيلاين بيضوى معرفى گرديدند. از طريق تحديد فضاى هيلبرت مورد مطالعه به كليه هارمونيكهاى بيضوى، تعريف

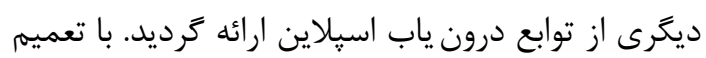
توابع گرين نظيرعملحرهاى بالاتر از مرتبه دو، فضاى هيلبرت ديخرى معرفى گرديد. اين فضا بستار كليه توابع مشتقيذير از مرتبه متناهى خاصى است. با توجه به ساختار اين فضا، هسته بازتوليد نظير آن و نيز

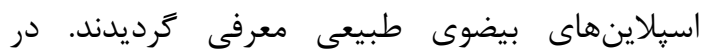

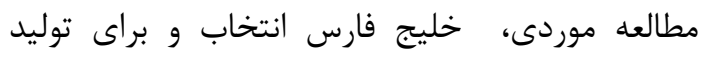
دادههاى شتاب ثقل در سطح دريا از زريد سطح متوسط دريا و تصحيح ديناميكى تويوگرافى سطح دريا استفاده شد. در مرحله نخست ارتفاع زئوئيد به دست آمد. در مرحله دوم، ارتفاع زئوئيد توسط رابطه برونز 


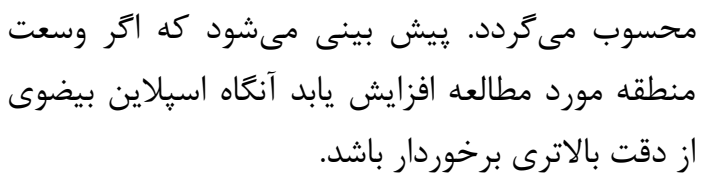

[1] P. Vanicek, R. O. Castle, and E. I. Balazs, "Geodetic Levelling and its Applications", Reviews of Geophysics and Space Physics, vol. 18, pp. 505-524, 1980.

[2] O. B. Anderson, P. Knudsen, "Global Marine Gravity Field from the ERS-1 and Geosat Geodetic Mission Altimetry", Journal of Geophysical Research, vol. 103, pp. 8129-8137, 1998.

[3] W. Freeden, M. Z. Nashed, and M. Schreiner, Spherical Sampling. Germany: Springer, 2018.

[4] W. Freeden, M. Gutting, Applied and Numerical Harmonic Analysis. Germany: Springer, 2013.

[5] W. Freeden, M. Gutting, Integration and Cubature Methods: A Geomathematically Oriented Course. New York: Chapman \& Hall(Taylor \& Francis Group), 2018.

[6] W. Freeden, On the Permanence Property in Spherical Spline Interpolation. Ohio: The Ohio State University, 1982.

[7] W. Freeden, T. Gervens, M. Schreiner, Constructive Approximation on the Sphere. England: Oxford University Press, 1998.

[8] W. Freeden, Spherical Spline Interpolation: Basic Theory and Computational Aspects. Germany: Institut Fur Reine Und Angewandte Mathematik, 1984.

[9] W. Freeden, Spherical Functions of Mathematical Geosciences. Germany: Springer, 2009.

[10] W. Freeden, "On Spherical Spline Interpolation and Approximation", Mathematical Methods in the Applied Sciences. vol. 3, pp.551-575, 1981.

[11] G. Wahba, "Spline Interpolation and smoothing on the sphere", Society for

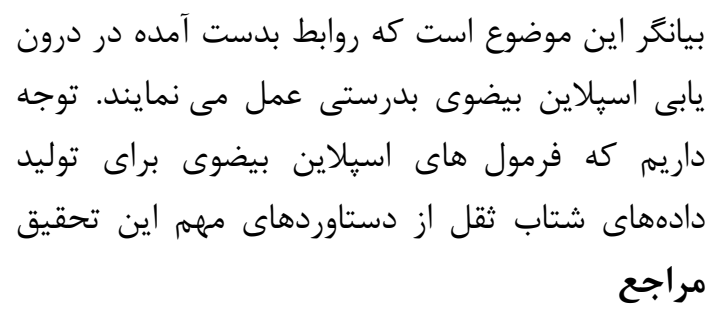

Industrial and Applied Mathematics, vol. 2, pp.1-10, 1981.

[12] G. Wahba, "Spline Models for Observational Data", presented at the Regional Conference in Applied Mathematics, Pennsylvania, 1990.

[13] N. Akhtar, V. Michel, "Reproducingkernel-based Splines for the Regularization of the Inverse Ellipsoidal Gravimetric Problem", Applicable Analysis, vol. 91, pp.2105-2132, 2012.

[14] A. Safari, M. A. Sharifi, H. Amin I. Foroughi, "Gravity acceleration at the sea surface derived from satellite altimetry data using harmonic splines", Journal of the Earth and Space Physics, vol. 40, pp.35-46, 2014.

[15] V. Baramidze, M. J. Lai, and C. K. Shum, "Spherical Splines for Data Interpolation and Fitting", Society for Industrial and Applied Mathematics, vol. 28, pp.1-19, 2006.

[16] E. Kreyszig, Introductory Functional Analysis with Applications. New York: John Wiley and sons, 1978.

[17] M. D. Greenberg, Application of Green's Functions in Science and Engineering. New York: Prentice Hall, 2015.

[18] L. B. Felsen, N. Marcuritz, Radiation and Scattering of Waves. New York: John Wiley \& Sons, 1994.

[19] M. Kiani, N. Chegini, A. Safari, B. Nazari, "Spheroidal Spline Interpolation", under review.

[20] R. Szmytkowski "Closed Form of the Generalized Green's Function for the Helmholtz Operator on the Two Dimensional Unit Sphere", Journal of 
Mathematical Physics, vol. 47, pp.303-321, 2006.

[21] M. C. Kim, B. D. Tapely, and C. K. Shum, "Mean Sea surface model", presented at the Center for space research, Pasadena(California), 1995.

[22] R. H. Rapp "The Development of a Degree 360 Expansion of the Dynamic Ocean Topography of the POCM-4B Global Circulation Model", presented at the NASA/CR-1998-206877 Goddard Space Flight Center, Greenbelt MD, 1998.

[23] C. Forste, F. Flechhtner, R. Schmidt, U. Meyer, R. Stubenvoll, F. Barthelmes, R. Konig, K. H.

Neumayer, M. Rothacher, C. H. Reigber, R. Biancale, S. Bruinsma, J. M. Lemoine, J. C. Raimondo "A new high resolution global gravity model derived from combination of GRACE and CHAMP mission and altimetry-gravimetry surface gravity data", presented at the EGU General Assembly, Vienna (Austria), 2005.

[24] C. Jekeli "The exact transformation between ellipsoidal and spherical harmonic expansions", Manuscripta geodaetica, vol. 13, pp.106-113, 1988.

[25] N. Chegini and R. Stevenson" Adaptive wavelet schemes for parabolic problems: sparse matrices and numerical results",SIAM journal on numerical analysis, vol 49, pp. 182-212, 2011.

[26] N. Chegini and R. Stevenson "An adaptive wavelet method for semi-linear first-order system least squares", Computational methods in applied mathematics, vol. 15, pp. 439-468, 2015.

[27] O. A. Oleinik, A. S. Shamaev, and G. A. Usifian," Mathematical Problems in Elasticity and Homoge -nization", Holland: Elsevier Science Publishers, 1992.

[28] M. Kiani shahvandi, Earth's Gravity Field
Modelling Using Spheroidal Spline, Ms.c thesis, School of Surveying and Geospatial Engineering, University of Tehran. 


\title{
Producing Gravity Acceleration at Sea Surface in Persian Gulf Using Ellipsoidal Splines
}

\author{
Mostafa Kiani Shahvandi ${ }^{1}$, Nabiollah Chegini $* 2$, Abdolreza Safari ${ }^{3}$, Borzoo Nazari ${ }^{4}$ \\ 1- Ms.c student of School of Surveying and Geospatial Engineering, University of Tehran, Tehran, Iran. \\ 2- Assisstant professor in Department of Mathematics, Tafresh University, Tafresh, Iran. \\ 3-Professor of School of Surveying and Geospatial Engineering, University of Tehran, Tehran, Iran. \\ 4- Assisstant professor in School of Surveying and Geospatial Engineering, University of Tehran, Tehran, Iran.
}

\section{Abstract}

In this paper, a method is proposed for producing gravity acceleration at sea surface in the Persian Gulf. This method is based on the Geoid height from satellite altimetry, high resolution Geopotential models, and ellipsoidal splines. First, the definition of the ellipsoidal spline functions is presented in a Hilbert space, which is consisted of infinitely often differentiable functions. In order to define the elipsoidal spline functions, the norm of the differential operators, including the Beltrami and Helmholtz in both the simple and iterated form, are minimized. In this respect, the reproducing kernels and the Green functions play an important role. The derived formulae are used to produce gravity acceleration at sea surface. To perform this method, the Geoid height, derived from satellite altimetry, is transformed into potential residual by Bruns formula. Then, the actual potential is derived by adding the Geoid's potential to the potential residuals. To obtain potential difference values, the effect of the reference field is subtracted from the actual potential values. By using ellipsoidal splines, the potential difference values are interpolated, which represent an analytical formula. By using the gradient of the analytical formula, we arrive at the gravity difference values. The removed effect of the reference field is added to the gravity difference values to obtain the gravity accelerations by adding the gravity values of a Geopotential model up to the degree and order 360, plus the centrifugal force. In the final step, the obtained gravity accelerations are moved to the sea surface using free air correction. A comparison between ellipsoidal and spherical splines is also presented.

Key words: Minimization of the norm of the differential operators, Reproducing kernels, ellipsoidal splines, data interpolation, gravity acceleration derived from Shipborne Gravimetry. 